\section{INTERNET GAMING AMONG CHILDREN IN THE TIME OF COVID-I9: AN EMERGING PSYCHOLOGICAL PROBLEM}

\author{
Abdul Wahab Yousafzai I ${ }^{\boxplus}$, Akhtar Sherin ${ }^{2}$
}

THIS ARTICLE MAY BE CITED AS: Yousafzai AW, Sherin A. Internet gaming among children in the time of COVID-19: an emerging psychological problem. Khyber Med Univ J 2020; I2(4): 26I-2. DOI: 10.35845/kmuj.2020.21046.

T he corona virus disease 2019 (COVID-19) has immensely changed the world landscapefrom economic, social and psychological adversities to the challenges of online education, exposing children to excessive screen-time using vast arrays of electronic devices. The online classes have become a valid reason for children to use internet more frequently with a growing possibility of misuse.

According to the WHO, as of April 2020, around I.5 billion children were out of schools, may be turning to online schooling, playing video games or socializing with peers online.' Furthermore, the anecdotal reports suggest that children after marking attendance in virtual classroom simultaneously, open gaming windows and start playing video games while still in the class and being unnoticed as away from the learning sessions. The unsupervised or loosely supervised children may be at higher risk of developing the psychological complication. One such complication is the Internet Gaming Disorder (IGD) which is a "persistent and recurrent use of internet to engage in games, often with other players, leading to clinically significant impairment or distress". 2 Similarly, the gaming disorder is being considered to be included as a diagnostic category in the WHO international classification of disease. ${ }^{3}$

The Diagnostic and Statistical Manual of Mental Disorders (DSM) based criterion of IGD includes:

(I) preoccupation with video games

(2) distressed feelings when away from video games (withdrawals)

(3) feeling the need to spend excessive amount of time playing the video games (tolerance)
(4) inability to control the participation in video games

(5) loss of interest in previously, enjoyable activities as a result of playing the video games

(6) persistently playing video games despite having knowledge of its harmful effects

(7) deceiving family member with regards to playing the video games

(8) using video games to ward off the negative feelings or boredom and

(9) impairment in social, occupational, academic functioning because of video games (negative consequences). ${ }^{4}$

The possibility among children developing IGD in the time of COVID-19 may be much higher than before due to their specific cognitive abilities and the valid reason for them to use internet.

Since tentative inclusion of IGD in the DSM classification in 2013, the disorder has been a focus of research attention. Although the literature about IGD is scarce in our part of the world, there is abundance of research emanating from the developed world, looking at the emerging diagnosis. Several large-scale studies have demonstrated that IGD is a real public health concern for children worldwide. ${ }^{5,6}$ For instance, studies using criteria similar to DSM-5, showed that $8.5 \%$ of youth aging 8 to 18 years in the US, ${ }^{7} 5.5 \%$ of adolescents aging 13 to 20 years in Netherlands ${ }^{8}$ and about $5 \%$ of students in Australia had IGD.

While the children may not be fulfilling the criterion of full blown IGD, the commonest manifestations of excessive screen-time among children have been widely reported. For instance, the
I. Member Editorial Board KMUJ, Professor \& Head of Psychiatry Department, Shifa College of Medicine, Shifa International Hospital Islamabad, Pakistan. Email凹: wahab.yousafzai@gmail.com

2. Chief Editor KMUJ, Professor of Medicine, Khyber Medical University Institute of Medical Sciences, Kohat, Pakistan.

children with excessive internet gaming are more likely to have craving for the screen associated mood disorders, irritability, impulsivity, attention deficit, conduct problem, emotional dysregulations and lower self-esteem. ${ }^{10}$

The biological consequences may include poor sleeping, unhealthy dietary habits, vision impairment, obesity, musculoskeletal problems and peripheral neuropathy. ${ }^{6}$ Similarly, the social repercussions include feeling of loneliness, poor communication skills, academic decline, distorted relationship with family members, lower self-esteem and being victims of cyberbullying. Furthermore, they are more prone to develop fantasies and psychological indoctrinations." Additionally, one of the serious implications of excessive internet use could be visiting of children, the websites, propagating pornography and religious indoctrination, thus making them vulnerable to the known harmful consequences.

While it may not be possible to shun internet use outrightly, yet stringent steps need to be taken to prevent children from developing the complications of excessive and unsupervised use of internet in the time of COVID- 19.

The way forward may be to structure the environment at home by setting the ground rules for screen time. By making sure that gaming devices and computer are located in living rooms, freeing the bedrooms of the gadgets, not allowing the children to play games at bedtimes and encouraging them to engage in physical activities. $^{12}$

Based on scientific findings, it is imperative for us to be aware of the physical, psychological and social deleterious effects of gaming disorder. Its high time for the parents, educationists and mental health professionals to raise the awareness about possible hazards of excessive use of screen time in the time of COVID-I9 and its physical and psychosocial complications. Parents need to make sure their children don't become victims of the harmful effects of internet by 
supervising their screen time and the scientific community should come forward to study the possible biopsychosocial consequences of internet gaming among children in our setting.

\section{REFERENCES}

I. World Health Organization. Mental health and substance use. Excessive screen use and gaming considerations during COVIDI9. . [Accessed on: November 22, 2020]. Available from URL: http://www.emro.who.int/ $\mathrm{mnh} /$ news/considerations-for-youngpeople-on-excessive-screen-useduring-covid 19.html

2. Conditions for Further Study. In: Diagnostic and Statistical Manual of Mental Disorders: DSM-5. American Psychiatric Publishing; Arlington VA: 2013. pp. 795-8.

3. World Health Organization. The ICDI I Classification of Mental and Behavioral Disorders: Diagnostic Criteria for Research. World Health Organization; Geneva, Switzerland:
2018.

4. Pontes HM, Griffiths MD. Measuring DSM-5 Internet gaming disorder: Development and validation of a short psychometric scale. Comput Human Behav 20I5 Apr 1;45:137-43. DOI: 10.1016/j.chb.2014.12.006.

5. Gentile DA, Bailey K, Bavelier D, Brockmyer JF, Cash H, Coyne SM, et al. Internet Gaming Disorder in children and adolescents. Pediatrics 2017 Nov I; 140 (Supplement 2):S8I5. DOI: I0.1542/peds.20I6-I758H.

6. Paulus FW, Ohmann S, von Gontard A, Popow C. Internet gaming disorder in children and adolescents: a systematic review. Dev Med Child Neurol 2018 Jul;60(7):645-59. DOI: I0.IIII/ dmcn. 13754 .

7. Gentile D. Pathological video-game use among youth ages 8 to 18: a national study. Psychol Sci 2009;20(5):594-602.

8. Lemmens JS, Valkenburg PM, Gentile DA. The Internet gaming disorder scale. Psychol Assess 2015;27(2):
567-82.

9. Thomas N, Martin F. Video-arcade game, computer game and Internet activities of Australian students: participation habits and prevalence of addiction. Aust J Psychol 2010; 62(2):59-66.

10. Strittmatter E, Kaess M, Parzer P, Fischer G, Carli V, Hoven CW, et al. Pathological Internet use among adolescents: Comparing gamers and non-gamers. Psychiatry Res 2015 Jul 30;228(I):128-35. DOI: 10.1016/ j.psychres.2015.04.029.

I I. Carlisle KL, Carrington C. The social experience of Internet gamers: A pilot study. VISTAS 20 I 5; I- I 3.

12. Krossbakken E, Torsheim T, Mentzoni RA, King DL, Bjorvatn B, Lorvik IM, et al. The effectiveness of a parental guide for prevention of problematic video gaming in children: A public health randomized controlled intervention study. J Behav Addict 20I8 Mar I;7(I):52-6I. DOI: |0.|556/2006.6.20I7.087
CONFLICT OF INTEREST

Authors declared no conflict of interest GRANT SUPPORT AND FINANCIAL DISCLOSURE NIL (c) (1) \$ BY NC
This is an Open Access article distributed under the terms of the Creative Commons Attribution-Non Commercial 2.0 Generic License.
KMUJ web address: www.kmuj.kmu.edu.pk Email address: kmuj@kmu.edu.pk 